\title{
The Influence of Leadership in Informal Learning of Multigenerational Teams
}

Roza Marsaulina Sibarani

\author{
School of Business and Management, Bandung Institute of Technology
}

roza@sbm-itb.ac.id

\section{Professor Dr. Jann Hidajat Tjakraatmadja}

School of Business and Management, Bandung Institute of Technology

Professor Utomo Sarjono Putro, PhD

School of Business and Management, Bandung Institute of Technology

\author{
Dr. Ningky Sasanti Munir
}

PPM School of Management

\section{Doi:10.5901/mjss.2015.v6n4p411}

\section{Abstract}

Several research papers focussing on the role of leadership in organizational learning have been published. In contrast, few papers been published on the role of leadership in informal team learning. This study examines the role of team leadership in informal learning, specifically in a multigenerational team. The way team leadership affects the team climate consequently influences informal team learning. Three latent variables were hypothesized to have a positive effect on informal team learning, which in turn was expected to improve the speed of task accomplishment. Data was collected from a qualitative study with 21 interviewees and a quantitative survey study with 184 respondents. Structural Equation Modelling was used to test the model. The results provided strong support for two out of three of the proposed latent variables. Team leadership influenced team climate significantly, but team leadership did not have a direct impact on effective informal team learning while the team climate did. The theoretical and managerial implications of these results are discussed.

Keywords: Team Leadership, informal learning, multigenerational workforce

\section{Introduction}

Most of the learning in an organization happens informally. A study conducted by Eichinger at the Center for Creative Leadership showed that formal courses only account for 10\% of total learning (Kajewski and Madsen, 2012). Eichinger developed a '70:20:10 model' in the 1980s that showed that 70 per cent of the learning in an organization was the result of job experience, assignments, and problem solving; 20 per cent of learning resulted from interaction with others such as feedback and good or bad examples; and the remaining 10 per cent of learning was accomplished with formal courses. Other studies have shown that formal and structured trainings account for only 20 per cent of what employees learn (Marsick and Watkins, 1990; Cross, 2007).

In businesses, informal learning helps organizations to manage training costs. It may reduce training costs, which is very helpful for medium to small-size organizations with limited training budgets. Informal learning also changes recruitment preferences. In the future, organizations will prefer to recruit informal learners who are eager to learn by themselves (Gorard et al, 1999).

In an organization, learning occurs at a unit or team-level (Senge et al, 1990; Tjakraatmadja and Lantu, 2006). Since learning is a key task for teams, the authors focused on studying informal learning at the team level. Since a team has processes and goals, a team leader should facilitate the informal learning within his team.

The other main issue in an organization is a multigenerational workforce. Each generation has a different background and it creates different traits and personal values. Baby boomers, who were born between 1945 and 1964, are world history witnesses that are used to working and communicating in a conservative way. Generation X, who were 
born in the MTV-era, are affected by the freedom to explore and be creative (Nicholas, 2009), and generation $Y$, who were born after 1980, are very close to technology and the internet. Can you imagine those three generations working together in a team? Different ways of communication, work and learning styles may inhibit their understanding of each other.

This research explores the role of leadership in reinforcing informal learning capabilities in a team that consists of multigenerational team members. The outcomes of this study imply that management should facilitate informal learning by creating team climate for learning. It was conducted using literature studies, a qualitative study in a medium-sized Indonesian consulting firm, and a quantitative study from teams working in many different Indonesian organizations.

This empirical research seeks to fill the gap in the literature by examining data from a consulting firm in a qualitative study and in quantitative study of more than 50 organizations in various industries. It also provides new insights regarding the role of team leadership in informal team learning. The paper starts with a literature review on informal learning, team leadership's role in developing informal learning capability, team climate for learning and effective informal team learning as an informal learning result, followed by the methodology of the empirical research. The findings of the qualitative and quantitative studies are presented further on. In addition, this paper concludes with a discussion and management application.

\section{Literature Review}

\subsection{Informal learning}

The concept of informal learning is derived from the term of "lifelong learning" (Alonderiene, 2010). We have informally learned since we were very young; we learned how to eat, read, jump, wear clothes, ride a bike, and other activities. When we went to school, we experienced both formal and informal learning. We studied math, science and english in school formally, and we also learned how to play hide-and-seek and how to tidy our toys informally. We have always been practicing both formal and informal learning.

In the workplace, informal learning is described as the learning processes that are the unofficial, unscheduled and impromptu way employees learn in order to do their jobs (Cross, 2007). Informal learning is like riding a horse, which the equestrian chooses the destination and route. The equestrian can take a detour in his trip or stop a while to help a fellow equestrian.

Informal learning is important in business. Most of the learning processes used in accomplishing our tasks are informal. Calling a friend in next cubicle to ask for a solution to our problem, or discussing a new project with colleagues in a café both are examples of informal learning. Informal learning can also be done through media, such as browsing information from the internet or having a discussion through a messenger group i.e. Blackberry messenger group or WhatsApp group. However, informal learning does not replace formal learning; rather they complement each other (Svensson et al, 2004).

Informal learning has been studied for some professions, for instance schoolteachers, nurses, bankers, European Union managers and social workers (Gola, 2009; McNally et al, 2009; Ryan et al, 2009; Chivers, 2010; Bjork et al, 2013). Relating to a business process, a study has shown that informal learning is very useful when the organization has to restructure, merge or downsize (Reardon, 2004). It is difficult to find training program for employees related to those kinds of conditions, thus most of organizations rely on informal learning.

Related to technology, open source software, namely SCORM (Sharable Content Object Reference Model), has been developed since 2004 to help people to learn (Advanced Distributed Learning, 2012). This technology not only saves the learner profiles, but also tracks the learner's experience and competency networks around the learner.

\subsection{The role of team leadership}

Team learning is described as the process of a group of individuals to act and make changes as the result of reflection of learning such as that obtained from feedback (Bucic et al, 2010; Edmondson, 1999). Since it is done collectively in a team, facilitation is necessary to enable flexibility, team knowledge sharing and individual competencies in order to create an effective team process and achieve the goal (Day et al, 2004 in Bucic et al, 2010).

The team leader is a facilitator in an informal team learning process. The team leader has two roles in creating effective informal team learning. First, the team leader creates a conducive team climate for knowledge creation (Marsick and Watkins, 1990, 2003, Nonaka et al, 2001). The more conducive the climate, the better, faster and more creative the informal learning process will be. 
Secondly, a team leader has a role in influencing team members in learning informally. Employees who receive more information and support from their leader and who engage in tasks and team, are expected to have more positive work attitudes and to engage in more positive behaviours compared with employees whose support is limited (Van der Klink et al, 2014).

In a multigenerational team, a team leader should be able to understand the learning style differences of each generation. Baby boomers, for instance, prefer to learn by sitting in a classroom workshop for training programs, and generation $Y$ can learn quickly through online media. By understanding this, a team leader can influence them personally to optimize their informal learning habits. Since generation $Y$ is very close to technology, a team leader should understand technologies that support informal learning.

Those two roles of leaders in team learning are influenced by the style of team leadership. Bucic et al (2010) studied leadership styles of transformational, transactional or ambidextrous, which effected to operational on learning development as a strategic resource. The ideal leadership style is the ambidextrous leadership approach, characterized by a combination of transformational and transactional leadership style (Bucic et al, 2010).

The research done by Srivastava et al (2006) and Xue et al (2010) showed that empowering leadership is the most relevant leadership style to enable knowledge sharing. The indicators of empowering leadership style are; leading by example, participative decision-making, coaching, informing, and showing concern for the team (Arnold et al, 2000).

The other leadership approach is shared leadership. Mealiea and Baltazar (2005) studied that an effective team requires shared leadership. In this leadership approach, the team leader has a role as contributor, collaborator, challenger, facilitator and controller.

From a study conducted by McKinsey in 81 organizations in Asia, Europe and America, there are 20 top kinds of leadership behaviours and the four selected behaviours drive up to 89 per cent of leadership effectiveness (Feser et al, 2015). Those four are being supportive, operating with a strong results orientation, seeking different perspectives and solving problems effectively.

However, those leadership styles discussed above were studied in regards to knowledge sharing processes in general, and not specifically in an informal learning process. In this research, the characteristics of leadership style above are used as indicators of team leader, and to be tested in both qualitative and quantitative studies.

H1. Team leadership will have a direct and positive effect on team climate.

H2. Team leadership will have a direct and positive effect on effective informal team learning.

\subsection{Conducive team climate}

Having discussed the literatures of informal learning and team leader, we now focus on the environment for team to learn informally. Experimentation, reflective communication and knowledge codification are learning actions for teams (Gibson and Vermeulen, 2003). Those learning actions will go well if supported by a comfortable learning environment that we called the team climate. The team climate encourages people to create, share, store, use and re-use knowledge.

Developing a learning climate requires psychological safety (Edmondson, 1999) and emotional intelligence (Ghosh et al, 2010). These are two necessary factors, because informal team learning is mostly interaction between individuals. People want to share knowledge if they feel safe and comfortable in their environment and with their colleagues.

A pre-condition for sharing knowledge requires shared values, care, trust, available time and information, and work variation (Bjork et al, 2013) and communication climate (Van den Hooff and de Ridder, 2004). Communication climate characteristics are open for information exchange, employees' accessibility, and cooperative interactions.

Not just influenced by the leader, the team climate is also affected by the systems in an organization (Mealiea and Baltazar, 2005) such as a learning system (Jones et al, 2003; Gibson and Vermeulen, 2003). Information technology and human capital systems support informal learning processes. Information technology such as open communication channels enables people to share knowledge through media such as intranet portal and social media. Creating a team climate for learning should use new technology that will result to higher efficiency, fewer errors and a more positive experience to employees (Reardon, 2009). A performance management system is an example of human capital system. In addition, performance management reviewed by external leader is one of the systems so as not to bias in judgment (Gibson and Vermeulen, 2003). Human capital can also stimulate coordination, communication, motivation, and improved team creativity (Tagger, 2002).

Mealiea and Baltazar (2005) studied the characteristics of a team associated with team performance. Their study showed that characteristics such as goal setting, willingness to listen and to share, open communication, style diversity, networking, and participation are important for team performance.

Goal setting allows team members understand what they need to achieve. A willingness to listen and to share is a 
driver for knowledge sharing. Open communication is the foundation for sharing relevant information and provides relevant feedback. Style diversity occurs when a team tolerates each other's styles and behavioural differences. Networking reflects team members' ability and willingness to connect to others especially experts in both internal and external organizations. Participation of team members in team activities and decisions makes them part of the team.

Learning culture in organization is often measured using Dimensions of the Learning Organization Questionnaire $\odot$ (DLOQ๑) that was developed by Marsick and Watkins (2003). DLOQ๑ is used to identify seven action imperatives of an organizational learning culture. Those seven actions are as follows: continuous learning, inquiry and dialogue, team learning, embedded systems, empowerment, connection to environment and strategic leadership (Pantouvakis and Bouranta, 2013).

Since we are specifically studying the multigenerational team, we must pay attention to team heterogeneity. Team heterogeneity influences trust, attitude toward experimentation, creativity, interaction between team members and consensus forming (Gibson and Vermeulen, 2003). People from different demographic backgrounds have different viewpoints and learning styles. Tolerance and complete understanding of the learning purpose are indicators for this kind of situation.

Although there is no specific characteristic of team climate for informal learning, the characteristics mentioned in the literatures above are used as indicators for team climate and to be tested in both qualitative and quantitative studies.

H3. Team climate will have a direct and positive effect on effective informal team learning.

\subsection{Effective informal team learning}

Informal team learning works well if it is effective, which means team members actively contribute during the process, leaders influence the processes, the learning climate supports it and it has resulted in increasing team performance. Performance is defined as task accomplishment (Kostopoulos and Bozionelos, 2011; Prugsamatz, 2010; Ross et al, 2008) and employee satisfaction (Gladstein, 1984). Performance can be a financial, operational or behavioural accomplishment. A task or project is well accomplished if it is delivered with the right quality, quantity and within its deadline.

Moreover, good team performance also makes employees satisfied being in that team (Rowden and Ahmad, 2000 in Pantouvakis and Bouranta, 2013). Rowden and Ahmad (2000) studied small to mid-sized business in Malaysia where employees with opportunities to develop and learn when working express higher level of job satisfaction. If employees are satisfied and enjoy being part of a team, they will easily capture and share knowledge with others. It also improves their capability because learning makes people more competent in doing a job.

As shown in Figure 1, team leadership and team climate are the informal learning processes that result to effective informal team learning. Those three factors are latent variables in our conceptual model that were produced based on literature study.

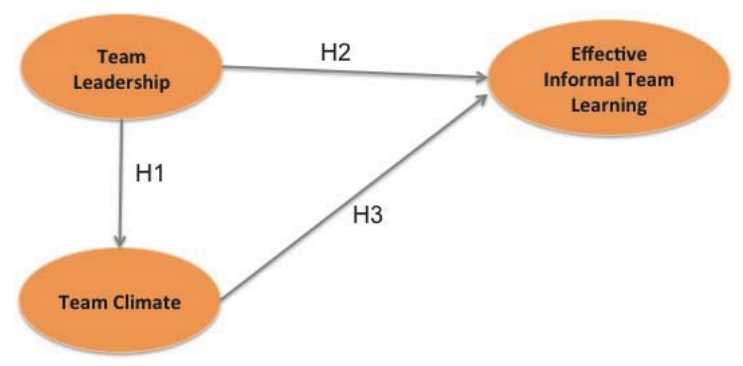

Figure 1. Conceptual model

\section{Methodology of Empirical Research}

\subsection{Qualitative research method and process}

The conceptual model, that was developed based on a literature study, was explored in a qualitative study. The study was done at a mid-sized consulting firm in Jakarta. It has licensees to deliver consulting and training services from global consulting firms based in USA. Having 138 full-time employees, this firm has seven multigenerational teams, functioning 
across its business, technical and support sectors. This firm was chosen because it is a knowledge intensive company, where people deal with a lot of knowledge in their daily activities.

A total of 21 respondents from those seven teams were interviewed. A semi-structured interview method was used. The interviewees were baby boomers, generation $X$ and generation $Y$, who represented the business, technical and support function teams. The majority of respondents were team members and five of them were team leaders. Observations at this firm were been taken over a two-year period. One of the authors is an employee at the firm, so the observations were intensive.

The interviews were transcribed and analysed using NVIVO 10 software. The three latent variables described in the conceptual model were formulated based on both the literature and qualitative studies.

\subsection{Quantitative research method and process}

A quantitative study was done after the qualitative study to confirm the findings in qualitative study. Both online and offline questionnaires were administered to collect data from respondents. The questionnaire was elaborated upon, based on the research model's qualitative study findings. The questionnaire was tested for clarity and relevance, with ten randomly selected people. After finalizing its format and content, the 85-item questionnaire was used for data collection.

The respondents were all employees in Jakarta that participated in public training programs held at the consulting firm. There were eight batches of training programs during December 2014. A total of 184 respondents participated in this survey. They represented staff, supervisors and managerial level in more than 50 organizations in Jakarta.

Some 66 per cent of respondents were male and 60 per cent of them were team leaders. Based on generational segregation, 54 per cent of respondents were from generation $\mathrm{X}, 38$ per cent were from generation $\mathrm{Y}$ and eight per cent were baby boomers. In relation to their work function, 22 per cent of respondents worked in business teams, 29 per cent in production teams and 49 per cent in support teams. Business teams were defined as those that generate revenue for the organization, a production team produces the goods or services for organization's clients, and a support team ensures that all business processes run smoothly.

In addition, 52 per cent of respondents were from service industries such as banks; insurance companies, telecommunication providers, software providers, distributors or public service companies; and 48 per cent were from manufacturing industries, such as oil and gas, fast moving consumer goods, pharmaceutical factories, automotive spare parts factories or companies in the property sector.

\section{Findings}

\subsection{Qualitative study findings}

The conceptual model was enriched by the qualitative study. The hypotheses were proven. Team leadership does indeed influence team climate and it also influences effective informal team learning. Team climate also has a direct influence on effective informal team learning. However, in field research, some of the indicators are slightly different from the literature, as shown in Figure 2, and we used the indicators based on the qualitative study.

From qualitative study, a team leader can lead a team if he first becomes a role model to his team. He does informal learning by himself before asking others to do the same. He also needs to be open for discussion, and open to receiving and giving feedback, which is the biggest part of the learning process. Since the teams consisted of multigenerational members, team leaders should be flexible with individual learning preferences because baby boomers, generation $X$ and $Y$ do indeed have different learning preferences. Team leaders should also be connected to many resources, both inside and outside the organization and both tangible and intangible resources, in order to find the right solutions for his team. In addition, generation Y respondents still need guidance from the team leader so that they can do the job right.

Trust is one of the important indicators in a team climate. If team members trust each other, they can easily capture and share knowledge with each other; this is also mentioned in literature studies. For sharing knowledge, they need to communicate well. Communication style and media preference might be different for each generation and therefore tolerance is necessary. Team climate is also built on openness. When people are open to each other, they can easily be reached and open to discuss with others, and they can easily share information and knowledge. Team climate is built upon when people have the habit of learning and sharing. Trust, communication and openness also influence this habit.

Team climate is not only influenced by the peoples' behaviour, but it also needs to be supported by the 
organization's system and facilities. Information systems, open office layout, rewards for sharing and innovating are some of the systems and facilities that should be provided by the organization.

The literature mentioned that informal learning process resulted in effective informal team learning including capability enhancement, and the qualitative study showed the same. All of the interviewees benefitted from informal learning, as their capabilities were increased. They could do more complex tasks and bigger projects. The qualitative study showed that effective informal team learning that was affected by informal learning increased its speed in accomplishing tasks. Team members could do their job from formal training, but informal learning helped them to learn quicker, thus they could finish their tasks in a shorter timeframe. Informal learning also connects them to many resources, both internal and external, that are very useful for accomplishing tasks.

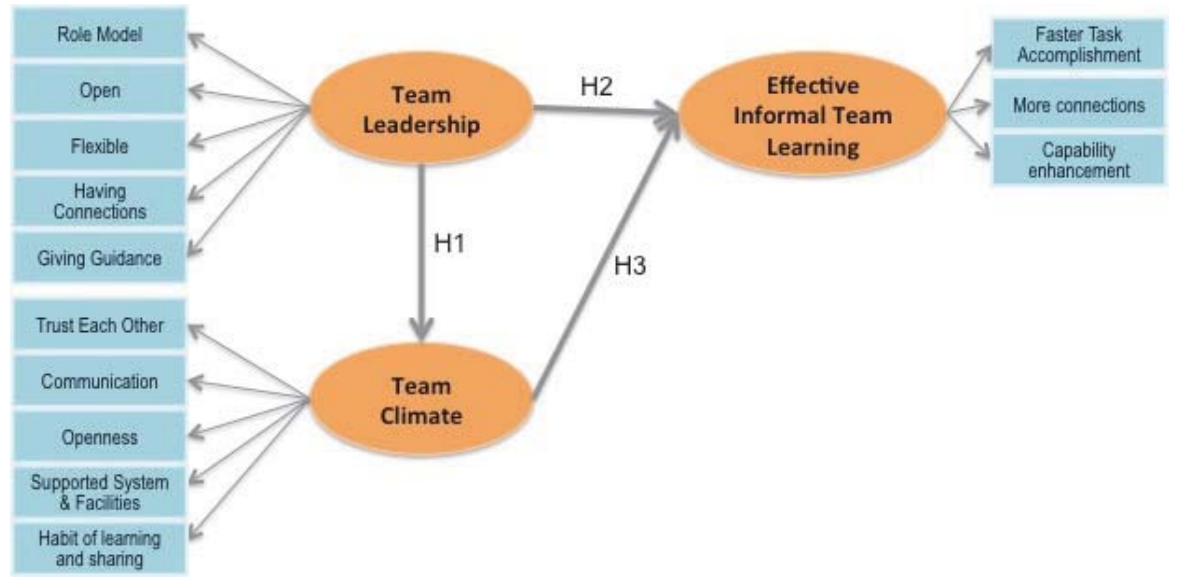

Figure 2. Research model with indicators for each latent variable from qualitative study

\subsection{Quantitative study findings}

The research model developed in the qualitative study as shown in Figure 2, was tested in a quantitative study. Since this research is about human behaviour, the measurement focuses on frequency. A five-point Likert scale ranging from "never" to "always" was employed. This measurement was chosen because behaviour frequency is more impacting than an 'agree' or 'disagree' statement. For instance, the question about team leader's openness did not measure whether team leader was open for discussion or not, but whether he was always or rarely open for a discussion.

The authors used Structural Equation Modeling (SEM) to validate the measurement and test the hypotheses. The SEM method was chosen because it is very useful in social science, where many key concepts are not directly observable (Westland, 2010). There were 184 people that participated in this survey, which is sufficient for SEM. Since early 1990s, researchers suggested having 10 observations per indicator for SEM (Westland, 2010). Since there were 13 indicators in our research model, as shown in Figure 2, the total respondents of this quantitative study was relevant. Hair et al (1995) suggested that minimum sample for SEM is 5 observations for each indicator. To test and analyze the hypotheses, Lisrel 8.3 software was used.

The structural model testing results are shown in Figure 3. This model has passed several criteria goodness of fit indices based on the guidelines for determining model fit.

a. The $p$-value $=0.98$ and the $\chi^{2}$-Chi-square is 11.97 ; these are accepted because the $p$-value is bigger than 0.05 and ratios for chi-square is not too large (Hulland et al, 1996; Hoper et al, 2008).

b. The Root Mean Square Error of Approximation (RMSEA) $=0.00$, and this is accepted because the well-fitting RMSEA is between 0 and 0.08 Hoper et al, 2008).

c. The Goodness-of-fit statistic (GFI) is non-statistical measurement that should range between 0 (poor fit) to 1 (perfect fit). The closer the number to 1 means the better fit the result (Hoper et al, 2008). In this test, GFI is 0.97 .

d. Adjusted goodness-of-fit statistic (AGFI) is 0.95 respectively. AGFI is generally accepted if the values are 0.90 or greater (Hoper et al, 2008).

e. Root mean square residual (RMR) and standardized root mean square residual (SRMR) are 0.04 and 0.067 respectively. Those two measurements are also accepted because they are less than 0.08 (Hulland et al, 1996; Hoper et al, 2008). 
The quantitative study showed that some indicators were rejected. In team leadership, the quantitative study showed that team leader does not have to be a role model for his team, or have connections to many resources in order to lead or facilitate informal learning within his team. These two indicators' $p$-value $=0.00$, and are thus rejected.

All of the indicators in team climate were accepted, with a $p$-value $=0.98$. Therefore, it is clearly shown that learning climate can be built if people trust, communicate, and are open with each other, have the habits of learning and sharing, and are supported by relevant systems and facilities.

Two indicators of effective informal team learning did not show significant relevance as an output of informal learning. The survey has shown that informal learning is very helpful for task accomplishment because people can do their job or finish the project in a shorter time, and this will certainly impact effective informal team learning.

The quantitative study showed that team leadership significantly affects team climate $(b=0.49$, t-statistics $=5.74)$, thus supporting $\mathrm{H} 1$. However, team leadership does not directly affect effective informal team learning, t-statistics was so low, at only 0.83 that $\mathrm{H} 2$ was rejected because t-statistics should bigger than 1.96 (Hair et al, 1995). Team climate is found to significantly affect effective informal team learning $(b=0.3, t$-statistics $=2.32)$, thus providing support for $\mathrm{H} 3$.

Table 1. Hypotheses test of Path Coefficients

\begin{tabular}{l|c|c|c|}
\hline Hypotheses & T-statistics & P-value & Result \\
\hline H1: Team leadership $\rightarrow$ Team climate & 5.74 & 0.98 & Accepted \\
\hline H2: Team leadership $\rightarrow$ Effective informal team learning & $0.8^{*}$ & 0.95 & Rejected \\
\hline H3: Team climate $\rightarrow$ Effective informal team learning & 2.32 & 0.98 & Accepted
\end{tabular}

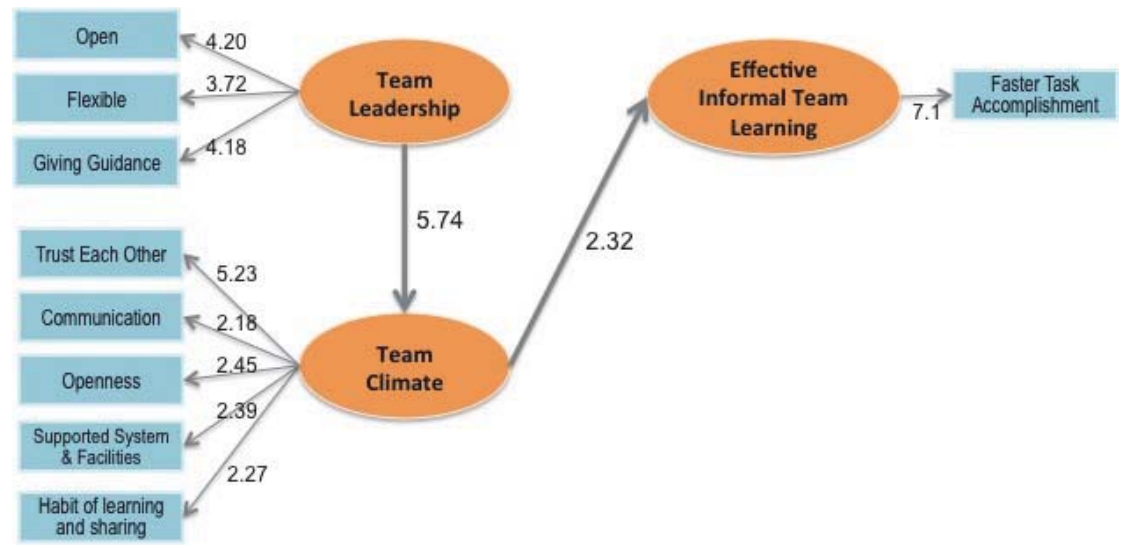

Figure 3. Final research model with factor loading and path coefficients for latent variables and indicators

\section{Discussion and Management Implications}

Even though the research done by Xue et al (2010) showed that both team climate and empowering leadership style influences people attitudes and knowledge sharing, this research showed that the team leaders only influences team climate in informal team learning. Therefore, the team leader should become a facilitator for creating a conducive team climate.

The indicators of team leader are being open and flexible. Team leader should encourage discussion, open feedback and tolerance of individuals' learning preferences. Moreover, since 35 per cent of the qualitative study respondents and 38 per cent of the quantitative study respondents are generation $Y$, they still need guidance from team leader, thus giving guidance is one of the indicators of team leadership in informal learning.

The indicators of team climate for informal learning processes, based on this research, are trust, communication, openness, habits of learning and sharing, and supported system and facilities. In addition, this research also showed that informal team learning would improve the effective informal team learning through faster task accomplishment.

Although this research has important implications on informal team learning, there were some limitations that relate to the respondents of both the qualitative and quantitative study, which might have limited the results applicability to be generalized for a wider business context. The respondents of the qualitative study were from a consulting firm, and might have different viewpoints from employees in other industries. Moreover, all of the respondents live in Jakarta, Indonesia, and might have different viewpoints and principles from other areas. 
In conclusion, this research furthers our understanding of the role of leadership in informal team learning for multigenerational team members. The findings are helpful for team leaders to facilitate informal learning within their team by creating team climate. A conducive team climate will help team members to accomplish their tasks faster, even though the team consists of multiple generations.

\section{References}

Advanced Distributed Learning (2012), Enabling Next Generation Learning with the Next Generation Learning Architecture, [Online] available: http://www.adlnet.gov/resources/enabling_next_gen_learning?type=presentation_(20 December 2014)

Alonderiene, R. (2010), Enhancing Informal Learning to Improve Job Satisfaction: Perspective of SMEs managers in Lithuania, Baltic Journal of Management, 5(2), 257-287.

Arnold, J. A., Arad, S., Rhoades, J. A., and Drasgow, F. (2000), The empowering leadership questionnaire: The construction and validation of a new scale for measuring leader behaviours, Journal of Organizational Behaviour, 21, 249-269.

Bjork, I. T., Toien, M., and Sorense, A. L. (2013), Exploring informal learning among hospital nurses, Journal of Workplace Learning, 25(7), 426-440.

Bucic, T., Robinson, L., and Ramburuth, P. (2010), Effects of leadership style on team learning, Journal of Workplace Learning, 22(4), 228-248.

Chivers, G., (2010), Supporting informal learning by traders in investment banks, Journal of European Industrial Training, 35 (2), 154175

Conference Board and DDI (2015), Ready-Now Leaders: Meeting Tomorrow's Business Challenges, Global Leadership Forecast 2014205, [Online] available: http://www.ddiworld.com/DDI/media/trend-research/global-leadership-forecast-2014-2015_tr_ddi.Pdf? ext=.pdf (14 February 2015)

Cross, J. (2007), Informal Learning: Rediscovering the Natural Pathways That Inspire Innovation and Performance, 10th edition, USA: Pfeiffer Books, John Wiley \& Sons Inc.

Day, D., Gronn, P. and Salas, E. (2004), Leadership capacity in teams, The Leadership Quarterly, 15(6), 857-880.

Edmondson, A. (1999), Psychological safety and learning behaviour in work teams, Administrative Science Quarterly, 44(2), 350-383.

Feser, C., Mayol, F. and Srinivasa, R. (2015), Decoding leadership: what really matters, McKinsey Quarterly, [Online] available: http://www.mckinsey.com/insights/leading_in_the_21st_century/decoding_leadership_what_really_matters (14 February 2015)

Gladstein, D. (1984), Groups in context: a model of task group effectiveness, Administrative Science Quarterly, 29(4), 499-517.

Gola, G. (2009), Informal learning of social workers: a method of narrative inquiry, Journal of Workplace Learning, 21(4), 334-346.

Gorard, S., Fevre, R. and Rees, G. (1999), The apparent decline of informal learning, Oxford Review of Education, 25(4), 437-456

Hair, J. F., Andreson, R. E., Tatham, R. L. and Black, W. C. (1995), Multivariate Data Analysis, 3rd edition, NY: Macmillan Publishing.

Hoper, D., Coughlan, J., and Mullen, M.R. (2008), Structural Equation Modeling: Guidelines for Determining Model Fit, The Electronic Journal of Business Research Methods, 6(1), 53-60.

Hulland, J., Chow, Y. H., Lam, S. (1996), Use of causal models in marketing research: a review, International Journal of Research in Marketing, 13(1996), 181-197.

Jones, E., Chonko, L. B., and Roberts, J. A. (2003), Creating a partnership-oriented, knowledge creation culture in strategic sales alliances: a conceptual framework, Journal of Business \& Industrial Marketing, 18(4), 336-352.

Kajewski, K. and Madsen, V. (2012), Demystifying 70:20:10, Whitepaper, [Online] available: https://www.deakinprime.com/deakinprime/ resources/pdf/whitepapers/DeakinPrime_70.20.10_WhitePaper.pdf (23 December 2014).

Kostopoulos, K. C. and Bozionelos, N. (2011), Team exploratory and exploitative learning: psychological safety, task conflict and team performance, Group and Organization Management, 36(3), 385-415.

Marsick, V. J. and Watkins, K. E. (1990), Informal and incidental learning, New Direction For Adult and Continuing Education, 89(spring).

Marsick, V. J. and Watkins, K. E. (2003), Demonstrating the value of an organization's learning culture: the dimensions of the learning organization questionnaire, Advances in Developing Human Resources, 5(2), 132-151.

Mealiea, L. and Baltazar, R. (2005), A strategic guide for building effective teams, Public Personnel Management, 34(2), 141-160.

McNally, J., Blake, A. and Reid, A. (2009), The informal learning of new teachers in school, Journal of Workplace Learning, 21(4), 322333.

Nicholas, A. J. (2009), Generational perceptions: workers and consumers, Journal of Business and Economics Research, 7(10), 47-52.

Nonaka, l., Toyama, R., and Konno, N. (2001), SECl, Ba and leadership: a unified model of dynamic knowledge creation. Managing industrial knowledge: creation, transfer and utilization, 145-169

Pantouvakis, A. and Bouranta, N. (2013), The link between organization learning culture and customer satisfaction: conforming relationship and exploring moderating effect, The Learning Organization, 20(1), 48-64

Prugsamatz, R. (2010), Factors that influence organizational learning in non-profit organizations, The Learning Organization, 17(3), 243267

Reardon, R. F. (2004), Informal learning after organizational change, Journal of Workplace Learning, 16(7), 385-395.

Reardon, R. F. (2009), The impact of learning culture on worker response to new technology, Journal of Workplace Learning, 22(4), 201211.

Ross, T. M., Jones, E. C. and Adams, S. G. (2008), Can team effectiveness be predicted?, Team Performance Management, 14(5/6), $248-268$ 
Rowden, R. W. and Ahmad, S. (2000), The relationship between workplace learning and job satisfaction in small to mid-sized business in Malaysia, Human Resource Development International, 3(3), 307-322.

Ryan, G., Emmerling, R. J. and Spencer, L. M. (2009), Distinguishing high-performance European executives: the role of emotional, social and cognitive competencies, Journal of Management Development, 28(9), 859-875.

Senge, P., Roberts, C., Ross, R., Smith B. L. and Kleiner, N. A (1990), The Fifth Discipline Field book: Strategies and Tools for Building a Learning Organization, $1^{\text {st }}$ edition, USA: Doubleday.

Srivastava, A., Bartol, K. M. and Locke, E. A. (2006), Empowering leadership in management teams: effects on knowledge sharing, efficacy and performance, Academy of Management Journal, 49(6), 1239-1251.

Svensson, L., Ellstrom, P-E. and Aberg, C. (2004), Integrating formal and informal learning at work, Journal of Workplace Learning, $16(8), 479-491$.

Tagger, S. (2002) Individual creativity and group ability to utilize individual creative resources: A multilevel model, Academy of Management Journal, 45, 315-330

Tjakraatmadja, J. H. and Lantu, D. C. (2006), Knowledge Management in Learning Organization Context, Indonesia: SBM ITB Publishers

Van den Hooff, B. and de Ridder, J. A. (2004), Knowledge sharing in context: the influence of organizational commitment, communication climate and CMC use on knowledge sharing, Journal of Knowledge Management, 8(6), 117-130

Van Der Klink, M.; Van der Heijden, B. I. J. M.; Boon, J. and Van Rooij, S. W. (2014), Exploring the contribution of formal and informal learning to academic staff member employability: a Dutch perspective, Career Development International, 19(3), 337-356

Westland, J.C (2010), Lower Bounds on Sample Size in Structural Equation Modeling, Electronic Commerce Research and Applications, [Online] available; http://indigo.uic.edu/bitstream/handle/10027/7655/Lower+bounds+on+sample+size+in+structural+equation+ modeling.pdf?sequence=3 (23 December 2014)

Xue, Y.; Bradley, J.; and Liang, H. (2010), Team Climate, Empowering Leadership and Knowledge Sharing, Journal of Knowledge Management, 15(2), 299-312. 